\title{
Comparison between one-step self-etch adhesive and along with additional hydrophobic layer in the retention of giomer at non-carious cervical lesion
}

\author{
Sultana Parveen, Mozammal Hossain, Md. Mujibur Rahman Howlader, Md. Abdul Hannan Sheikh, \\ Md. Shamsul Alam and Mohammad Ali Asgor Moral
}

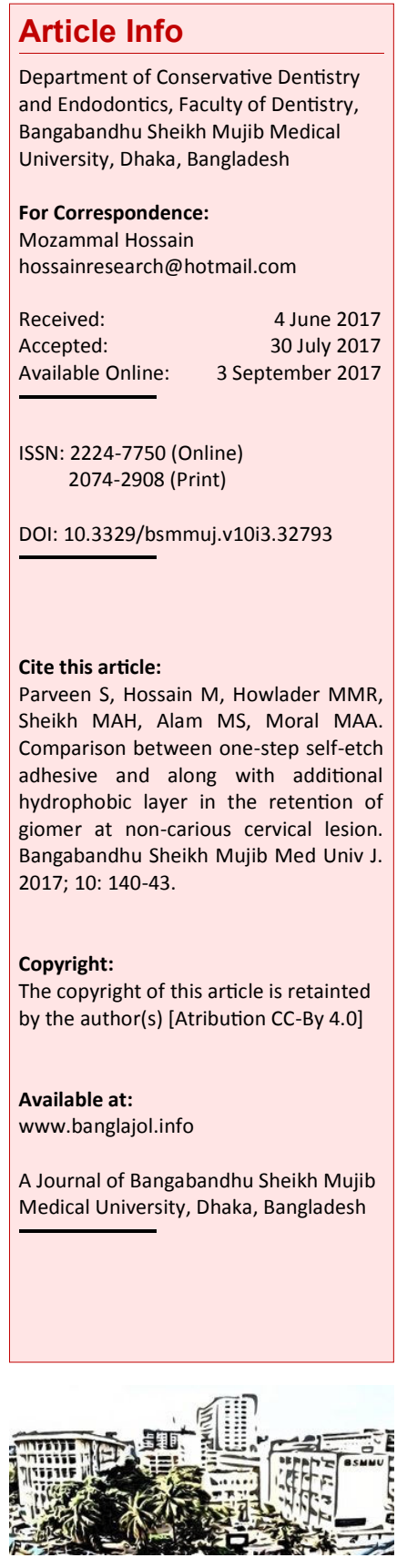

\section{Abstract}

The purpose of the present study was to assess the giomer retention following application of one step self etch adhesive and one-step self-etch adhesive plus an extra hydrophobic adhesive layer in non-carious cervical lesion. Twenty four participants having bilateral cervical lesion at the maxillary premolars teeth were selected. Following cleaning of the cervical lesions, 24 left premolar teeth were restored with giomer by using the one-step self-etch system (Group A) and 24 right premolar teeth were restored with giomer by using one-step self-etching plus extra hydrophobic adhesive layer (Group B). Participants were recalled at 6 and 15 months for evaluating the clinical outcome. The results showed that at 15 months, 18 giomer restorations in Group A and 21 in Group B were intact inside the cavity and no significant difference was found between the two groups. It can be concluded that giomer restoration used with one-step selfetching plus additional adhesive layer slightly improved the retention of the material.

\section{Introduction}

Non-carious cervical lesions (e.g. abrasion, erosion and abfraction) occurred due to loss of hard tissues at the cement-enamel junction or its adjoining one-third portion of the crown/ root.1 They are usually seen in the region of plaque accumulation such as near the gingival or under proximal contact. Furthermore, enamel is very thin in this area, many patients complain of severe sensitivity and it may affect the vitality of the pulp tissue. 1 Resin-based composite especially flowable composite materials have been used widely to restore non carious cervical lesion for its resiliency.2 However, marginal leakage, discoloration, polymerization shrinkage and post-operative sensitivity are the possible reasons for the failure of restoration. 3 To reduce this problem, fluoride has been added to the materials. $.4,5$ Several fluoride-containing materials such as resin modified glass ionomer, $\underline{6}$ compomer, $\underline{\underline{ }}$ fluoridecontaining resin-based composite, 7 have been developed.

In recent years, giomer restorative material has been introduced and its application in the dental clinic has been expected. 8 Giomer is composed of glass ionomer and composite and therefore considered as having properties of both glass ionomer and resin composite.
However, the bond of giomer requires an intermediary agent for bonding to tooth structure. Therefore, the use of resin bonding system has been proposed. 9 Seventh-generation systems (also called one-step self-etching system) combined etchant, primer, and adhesive in a single bottle thus eliminating an additional mixing and/or placement step over the sixth, fifth and fourth-generation systems. It is composed of high concentration of hydrophilic resin monomers, ionic resin monomers or both. $\underline{10}$ It creates thin coating that may inhibit oxygen and result in a poorly polymerized adhesive layer.11

The monomers are also prone to phase separation, $\underline{12}$ because the solvent evaporates from the solution which behaves like a permeable membrane after polymerization. $\underline{13}$ This is due to the lack of the non-solvent hydrophobic layer, $\underline{14}$ and allows for rapid dentinal fluid transudation across the polymerized adhesive. 15 However, the result of some laboratory studies have indicated that treating a onestep self-etch system as a primer and covering it with a more hydrophobic adhesive layer (that is converting the one-step self-etch systems into a two step system) could reduce the one-step selfetch system drawback. 16,17 The application of hydrophobic adhesive layer may also prevented the degradation of the resin dentin bonds of 
three one-step self-etching system after six months of water storage, $\underline{\underline{17}}$ Therefore, it can be considered that in addition to one-step self-etch system, the use of an extra hydrophobic adhesive layer might be more effective to improve retention of a restoration in clinical practice, especially in non-carious cervical lesion.

The purpose of the present study was to examine whether giomer retention could increase following application of one-step self-etch adhesive plus an addition of extra hydrophobic adhesive layer in non -carious cervical lesion (abrasion) and compared its effectiveness with that of one-step self-etch adhesive, in vivo.

\section{Materials and Methods}

\section{Study population}

Twenty four participants having bilateral cervical lesions (abrasion) at the maxillary premolars teeth who attend the outpatient clinic were selected for this study. Inclusion criteria was as follows: noncarious cervical lesion (abrasion) with vital pulp, axial wall: within 1-2 $\mathrm{mm}$. mesio-distal length of lesion: from 0.5 to $2.5 \mathrm{~mm}$. occlusal-gingival length of lesion: 0.5 to $3 \mathrm{~mm}$. Age range of the subjects was ranged between 20 to 60 years. Exclusion criteria included carious cervical lesion, axial wall depth greater than $2 \mathrm{~mm}$ and smoker patient.

\section{Tooth preparation}

Following cleaning of each cervical lesion with
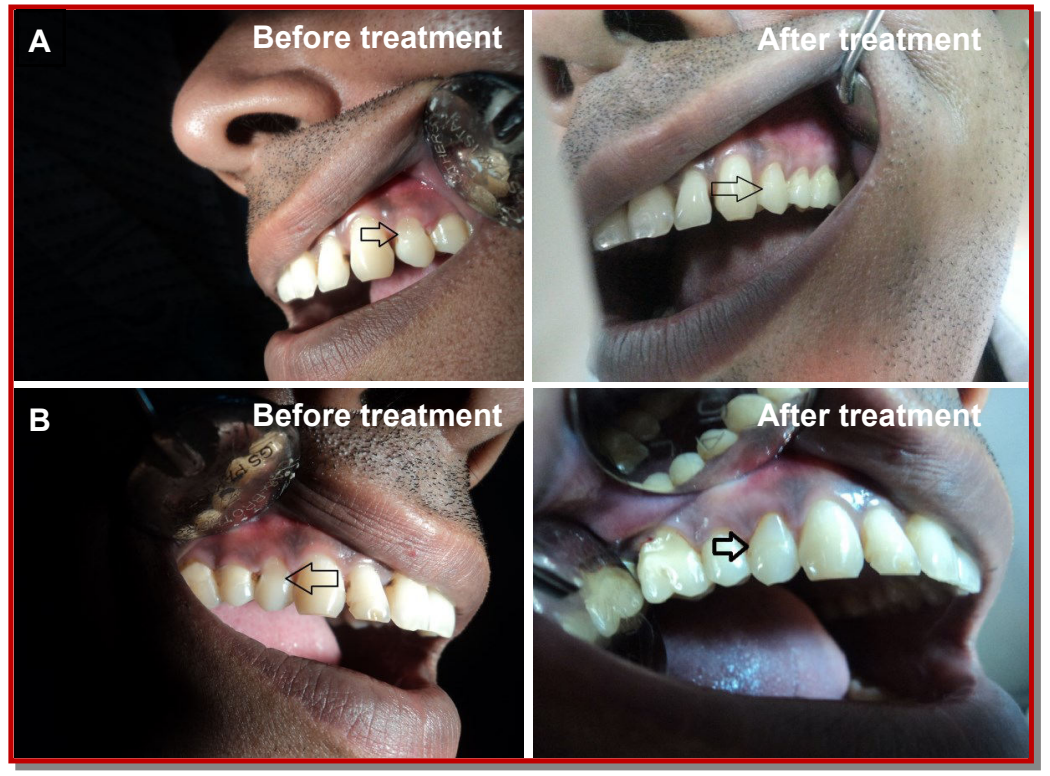

Figure 1: Representative photographs of giomer restored with one-step self-etch adhesive (A) plus an additional hydrophobic layer (B). The restorations were intact throughout the observation period before and 15 months after treatment. Arrow indicates the treated tooth pumice powder, tooth was isolated with cotton roll and used a suction device during the restorative procedure. When tissue retraction is not sufficient, a short length of gingival retraction cord was used to expose the lesion more clearly. Neither local anesthesia nor any retentive grooves or enamel bevels was not performed.

\section{Giomer restoration}

In Group A, the left permanent premolar teeth were treated as follows: after applying one-step self etch adhesive system (adper easy bond) by cotton stick and curing for $10 \mathrm{sec}$ and then giomer were placed into the lesions (Figure 1). Finishing and polishing of all restoration were performed by super snap polishing disk (Sofu, Japan).

In Group B, the right permanent premolars were treated according to the following techniques: following application of one-step self-etch adhesive system (adper easy bond) and curing for $10 \mathrm{sec}$. Then, an extra layer of hydrophobic adhesive (TeEconom Bond) were applied on it and curing for 10 sec and giomer were placed into the lesions (Figure 1). Finishing and polishing of all restoration were performed by super snap polishing disk (Sofu, Japan).

\section{Evaluation}

Patients were recalled at 6 and 15 months for evaluating the clinical outcome according to modified United States Public Health Service Criteria. $\underline{18}$ Clinical evaluation such as retention, color match, marginal adaption, surface roughness and postoperative sensitivity assessed at baseline, at 6 and 15 months. The retention was checked by using necked eye and explorer. To determine the color stability of the materials, one of them took intraoral color photographs immediately after insertion of the restorations at 6 and 15 months, and then compared with same tooth with the help of VITA shed guide. Surface roughness and marginal adaption were assessed by using a sharp explorer and post-operative sensitivity was evaluated with compressed air. Statistical analysis was carried out by using the Statistical Package for Social Sciences version 16.0 for Windows (SPSS Inc. USA) and the differences between the materials were assessed by using the Chi-square test and a value of $p<0.05$ was considered as statistically significant.

\section{Results}

At 6 months observation period, all restorations were intact inside the cavity in both groups. Undetectable marginal adaption and smooth surface were present in both groups (Figure 1). All participants in Group A and Group B had no postoperative sensitivity and the differences between two groups were not statistically significant. 


\begin{tabular}{|c|c|c|}
\hline \multicolumn{3}{|l|}{ Table I } \\
\hline \multicolumn{3}{|c|}{ Evaluation of restoration at 15 months } \\
\hline Parameters & $\begin{array}{c}\text { Group A } \\
(\mathrm{n}=24)\end{array}$ & $\begin{array}{c}\text { Group B } \\
(\mathrm{n}=24)\end{array}$ \\
\hline \multicolumn{3}{|l|}{ Retention } \\
\hline Restoration intact inside the cavity & 18 & 21 \\
\hline Partial loss of restoration but can be repaired & 4 & 3 \\
\hline Total loss and need replacement & 2 & 0 \\
\hline \multicolumn{3}{|l|}{ Color match } \\
\hline Excellent & 10 & 11 \\
\hline Slight mismatch & 14 & 13 \\
\hline \multicolumn{3}{|l|}{ Marginal adaptation } \\
\hline Undetectable & 18 & 21 \\
\hline Explorer catches & 6 & 3 \\
\hline \multicolumn{3}{|l|}{ Surface roughness } \\
\hline Smooth surface & 18 & 21 \\
\hline Slightly rough or pitted & 6 & 3 \\
\hline
\end{tabular}

Evaluation at 15 months showed that 18 giomer restorations in Group A and 21 in Group B was intact inside the cavity. Fourteen giomer restorations in Group A and 13 in Group B was slight mismatch in color. Furthermore, 21 restorations in Group B and 18 cases in Group A, undetectable marginal adaptation and smooth surface were evident. All patients in Group A and Group B had no post-operative sensitivity. No significant $(p>0.05)$ difference was found between the two groups (Table I).

\section{Discussion}

The results of the present study confirmed that the clinical outcome of giomer restoration used with one-step plus additional hydrophobic layer is slightly superior to that of conventional method. Furthermore, the results were corresponded to some of the previous studies that sealing ability of one-step self-etch adhesive in class $\mathrm{V}$ cavity preparations could be improved by the application of more hydrophobic resin layers. $\frac{19,20}{2}$ The adhesive layer may help to preserve the integrity of hybridized dentin, protecting it from polymerization shrinkage stress and acting as a stress absorbing layer. Application of non-solvent hydrophobic monomer increase the adhesive layer thickness leads to a thicker and more uniform adhesive layer with lower concentrations of retained water and solvent, which is known to reduce the detrimental effects of polymerization shrinkage of resin based composite restoration. $\underline{21}$

However, 2 restorations in Group A were replaced; the restorations were lost totally. Although, the reason of total loss of these 2 restorations were not clearly understood from the present study, but based on the previous study, it can be said that restorations were lost either due to adhesive failure or large polymerization shrinkage. 22 Furthermore, loss of restoration may also occur due to contamination at any step of the bonding process that can adversely impact the longevity of the restoration and hamper its clinical success. $\underline{23}$ Furthermore, 4 restorations in Group $A$ and 3 in Group B were partially lost at 15 months which was replaced by re-application of giomer. A careful examination of these restorations revealed that these restorations were replaced due to chipping of the materials. When marginal adaptation of these restorations was examined, it was found that explorer was penetrating or catches. Moreover, surface of these restorations were pitted or rough. Previous studies have indicated that surface roughness can result from the highly erosive wear of the materials and it leads to external discoloration since it tends to stain more than does a smoother surface. 23,24 Therefore, based on the present study and together with the previous studies it can be assumed that chipping of the material might occur due to the wear of the restoration.

The advantage of using an additional layer are as follows: a) the first layer of the adhesive begins to etch the dentin substrate, $b$ ) it might become rapidly buffered by the hydroxyapatite, $\underline{25}$ so that the additional layers of unpolimerized acidic monomers may improve the etching ability of these adhesives by increasing the concentration of acidic reagents. Simultaneously to this process, more impregnation of resin might occur. 26 The results found in the present study were corresponded to that of previous studies that giomer could also be used in the dental clinic with favorable clinical outcome when used with one-step plus additional hydrophobic layer.

\section{Conclusion}

Giomer restoration used with one-step plus addiional layer slightly improves its retention during 15 months of clinical evaluation.

\section{References}

1. Goel VK, Khera SC, Ratstne JL, Chang KH. Stress at the dentinoenamel junction of human teeth: A finite element investigation, J Prosthet Dent. 1991; 66: 451 -59 .

2. Kemp-Scholte CM, Davidson CL. Complete marginal seal of class $\mathrm{V}$ resin composite restorations effected by increased flexibility. J Dent Res. $1990 ; 696 ; 1240-43$ 
3. Okuyama K, Mttrata Y, Pereira PN, Miguez PA, Komatsu J, Sano H. Fluoride release and uptake by various dental materials after fluoride application. Am J Dent. 2006; 19: 123-27.

4. Itota T, Carrick TE, Yoshiyama M, Maccabe JF. Fluoride release and recharge in giomer, composer and resin composite. Dent Mater. 2004; 20: 789-95.

5. Honda T, Yamaoto K, Hirose M. Study on the film substance produced from S-PRG filler. J Conserv Dent. 2002; 45: 42.

6. Nishio M, Yamamoto $\mathrm{K}$. The anti-dental plaque effect of fluoride releasing light-cured composite resin restorative materials. J Conserv Dent. 2002; 45: 459-68.

7. Gorden W, Major JA. Short- and long-term clinical evaluation of post-operative sensitivity of anew resin based restorative material and self-etching primer. Oper Dent. 2002; 27: 543-48.

8. Sonoda H, Sasafuchi Y, Kitasako Y, Arakawa M, Otsuki M, Tagami J. Pulpal response a fluoride releasing all in one resin bonding system. Oper Dent. 2002; 27: 271-27.

9. Ansari AA. An evaluation of strength of composite restorations using different bonding agent: An in vitro study. J India Soc Pediat Prevent Dent. 2006; 22: 162-67.

10. Van Landuyt KL, Snauwaert J, De Munck J, Peumans M, Yoshida Y, Poitevin A. Systematic review of the chemical composition of contemporary dental adhesives. Biomater 2007; 28: 3757-85.

11. Pashley EL, Agee KA, Pashley DH, Tay FR. Effects of one versus two applications of an unfilled, all-inone adhesive on dentine bonding. J Dent. 2002; 30; 83-90.

12. Van Landuyt KL, Peumans M, De Munck J, Lambrechts P, Van Meerbeck B. Extension of a onestep self-etch adhesive into a multistep adhesive. Dent Mater. 2006; 22: 533-44.

13. Tay FR, Pashley DH, Suh BI, Carvalho RM, Itthagarun A. Single-step adhesives are permeable membranes. J Dent. 2002; 30: 371-84.

14. Cheong C, King NM, Pashley DH, Ferrari M, Toledano M, Tay FR. Incompatibility of self-etch adhesives with chemical/dual-cured composites: Two-step vs one-step systems. Oper Dent. 2003; 28: 747-55.

15. Itthagarun A, Tay FR, Pashley DH, Wefel JS, Garcia -Godoy F, Wei SH. Single-step, self-etch adhesives behave as permeable membranes after polymeriza- tion, part III: Evidence from fluid conductance and artificial caries inhibition. Am J Dent. 2004; 17: 394400 .

16. de Silva AL, Lima DA, de Souza GM, dos santos $\mathrm{CT}$, Paulillo LA. Influence of additional adhesive application on the microtensile bond strength of adhesive systems. Oper Dent. 2006; 31: 562-68.

17. Reis A, Albuquerque M, Pegoraro M, Mattei G, Bauer JR, Grande RH. Can the durability of onestep self-etch adhesives be improved by double application or by an extra layer of hydrophobic resin? J Dent. 2008: 36: 309-15.

18. Cvar JF, Ryge G. Reprint of criteria for the clinical evaluation of dental restorative materials. Clin Oral Investig. 2005; 9: 215-32.

19. Peumans M, Kanumilli P, De Munck J, Van Landuyt K, Lambrechts P, Van Meerbeek B. Clinical effectiveness of contemporary adhesives: A systematic review of current clinical trials. Dent Mater. 2005; 21: 864-81.

20. Pushpa R, Suresh BS. Marginal permeability of one step self-etch adhesive effect of double application or the application of hydrophobic layer. J Conserv Dent. 2010; 13: 141-44.

21. Choi KK, Condon JR, Ferracane JL. The effects of adhesive thinkness on polymerization contraction stress of composite. J Dent Res. 2000; 79: 812-17.

22. John W, Evancusky JW, Meiers JC. Microleakage of compoglass-F and Dyract-AP compomers in class$\mathrm{V}$ preparations after salivary contamination. Pediatr Dent. 2000; 22: 39-42.

23. De Gee AJ, van Duinen RN, Werner A, Davidson CL. Early and long-term wear of conventional and resin-modified glass ionomers. J Dent Res. 1996; 73: 1613-19.

24. Gladys S, Van Meerbeek B, Braem M, Lambrechts P, Vanherle G. Comparative physio-mechanical characterization of new hybrid restorative materials with conventional glass-ionomer and resin composite restorative materials. J Dent Res. 1997; 76: 883-94.

25. Swift EJ, Perdigao J, Heymann HO, Wilder AD, Bayne SC, May KN. Eighteen-month clinical evaluation of a filled and unfilled dentin adhesive. J Dent. 2001; 29: 1-6.

26. King NM, Tay FR, Pashley DH, Hashimoto M, Ito $\mathrm{S}$, Sunico M. Conversion of one-step to two-step self-etch adhesives for improved efficacy and extended application. Am J Dent. 2005; 18: 126-34. 